\title{
The archaeoastronomy of the megalithic monuments of Arles-Fontvieille: the equinox, the Pleiades and Orion
}

\author{
Morgan Saletta \\ University of Melbourne, Victoria 3010, Australia \\ email: msaletta@unimelb.edu.au
}

\begin{abstract}
The megalithic monuments of Arles-Fontvieille appear to have been deliberately constructed such that a ray of the setting sun on and around the equinox penetrates the subterranean chamber producing a spectacular light-and-shadow hierophany. Moreover, at one of the sites there is evidence in the form of rock art that observations were also being made of heliacal rising and settings, possibly of both the Pleiades and Orion. The equinox hierophany has been documented at three of the four intact monuments of the group. This phenomenon was probably exploited for sacred ritualistic purposes related to seasonal change and timekeeping by the agricultural people who built the monuments. This evidence has significant importance for understanding these monuments in the context of European megalithism and the wider European Neolithic as well as for understanding their cosmological role within the society that built them.
\end{abstract}

Keywords. megaliths, archaeoastronomy, cultural astronomy, hypogées, Pleiades, Orion, Neolithic France, passage graves, Arles-Fontvieille

\section{Introduction}

Few ancient monuments in Europe are as impressive and yet as relatively unknown and poorly understood as the megalithic monuments located near the small village of Fontvieille, outside of Arles in the south of France. In 1998 I had the opportunity to visit the one site then open to the public. The purpose of my trip was to test a hypothesis I had been entertaining regarding the sites since I had first become aware of them through the work of Glyn Daniel who had visited the sites in the late 1950s. Based on the map published in his work (Daniel 1960) I hypothesized that the east/west orientation of the monuments was not incidental, but deliberately aligned such that a ray of the setting equinoctial sun would penetrate the subterranean passages in a manner not unlike the well known winter solstice event at Newgrange, but hitherto unsuspected because of the largely subterranean nature of these remarkable monuments. In what follows I will present evidence of a deliberate equinoctial alignment of the monuments as well as rock art evidence of stellar observations at one of them and discuss how these findings may change the way we understand these sites within the larger context of European megalithism.

While the Arles-Fontvieille are among of the largest, most impressive and important Neolithic 'passage graves' in France they are not nearly so well known or so well studied as the monuments of Brittany and the Morbihan coast. Jean Guilaine (1998: 60) wrote "Par la qualité de leur architecture, ces tombs sont uniques dans tout le sud de la France". The largest of these monuments is, by its size, "le plus impressionant monument préhistorique de la France" (ibid.) and classified as one of the largest and most important megalithic monuments in France and in Europe by the most recent archaeologists to make a detailed on-site study (Arnal \& Latour 1953). Daniel argued for the importance of understanding 
these impressive monuments, writing "The problem of the chronology and interpretation of the Arles-Fontvieille tombs is a most crucial one - indeed, perhaps the most crucial one - in any analysis of the French megalithic tombs" (Daniel 1960: 161), and attempted to put them into a regional context.

The archaeological literature refers to them variously as passage tombs, grottes, hypogées, hypogea, allées couvertes and nécropoles. I have chosen to refer to them more generally as monuments, a term that leaves open the question of multiple uses (tomb, religious and ritual center) while accurately reflecting their nature. While in the past these monuments have largely been seen as tombs - the small number of human remains in several of the sites and the absolute lack thereof in the Grotte de Cordes suggests that they were primarily ritual cult centers rather than glorified tombs.

There are five monuments in the group. The largest is the Grotte de Cordes (known also as the Grotte des Fées or l'Epée de Roland) located on the Montagne des Cordes. The other four monuments are located on the neighbouring but much lower hill named Castelet. These are:

1. The Grotte Arnaud-Castellet

2. The Grotte Bounias

3. The Grotte de la Source

4. The Dolmen de Coutignargues

Four of the sites share an overall similarity of architectural structure and design. They are long trapezoidal rock-cut chambers of impressive size cut into the soft local bedrock and roofed over with megalithic slabs. They are accessed by a rock-cut ramp that leads to a portal into the main chamber, which in the case of the smaller sites ranges between $10 \mathrm{~m}$ and $12 \mathrm{~m}$ in length with a height of nearly $3 \mathrm{~m}$.

Within the group, the Grotte de Cordes (Fig. 1) is unique both in its size and the presence of two rounded 'antechambers', as well as a shorter passage or antechamber leading into the main chamber which measures an impressive $23 \mathrm{~m}$ in length (with an overall length for the monument of $43 \mathrm{~m}$ ).

A fifth site, while similar in shape and orientation, is not rock-cut, but made from dry walled stone and is presently in very poor condition. However, Sauzade (1977) argues convincingly that the dolmen of Coutignargues is a close copy of the other monuments representing a unique solution to areas where the bedrock was insufficient to allow the excavation and roofing of a long trench.

\section{The orientation and the equinoctial alignment}

Aside from the remarkable uniformity in architectural style, one of the most striking things about the group is the almost uniform alignment. The monuments are all aligned on an east-west axis, opening on the west. This is an unusual orientation for Mediterranean megaliths and European megaliths more generally (Hoskin 2001), which tend to be oriented eastward - toward the rising sun.

In 1997, at a graduate seminar at the École des Hautes Études en Science Sociales (EHESS) in Paris, I proposed that this orientation was likely to have a functional nature in that the rays of the setting equinoctial sun would penetrate the monuments - despite their subterranean nature - and strike the back wall. In 1998 I was able to document this phenomenon at the Hypogée d'Arnaud-Castellet, the only monument then open to the public. While other authors have remarked on the orientation in passing, and others have highlighted its unusual nature, my hypothesis regarding the functional nature of the alignment was and is original. 


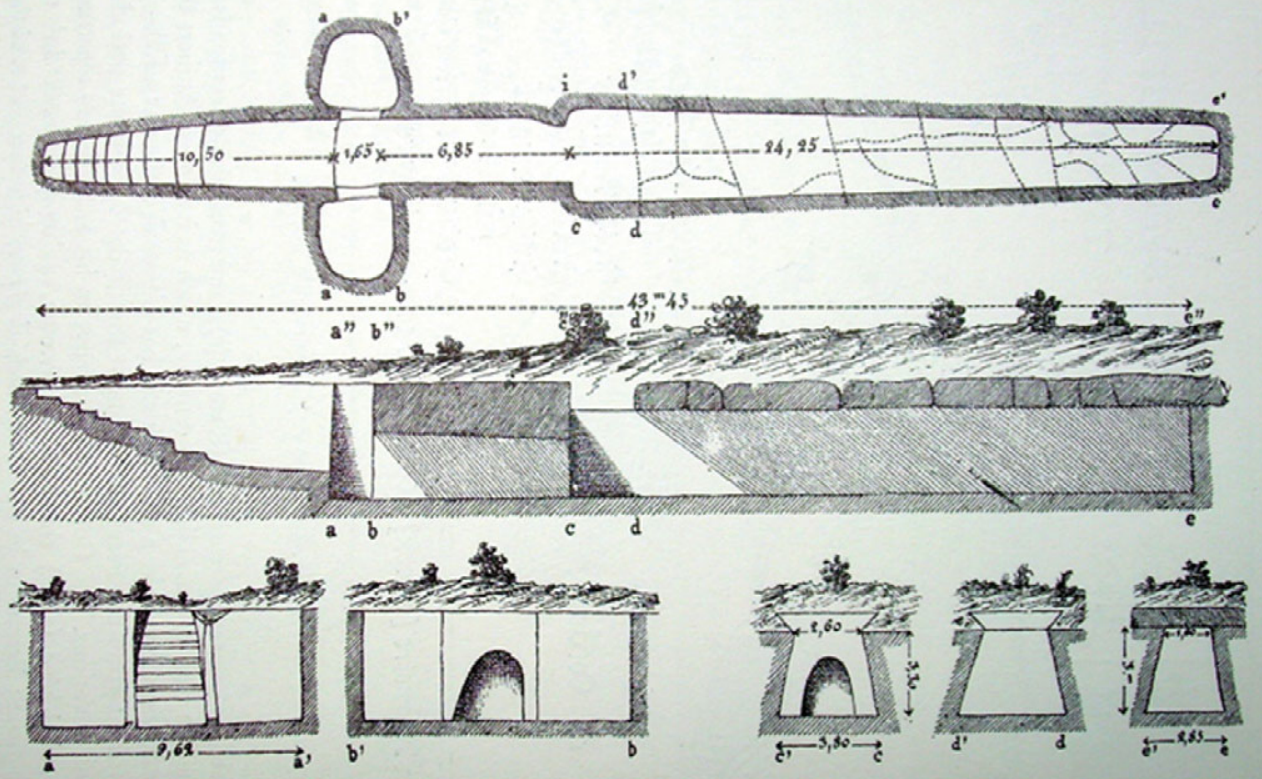

Fig. 59. Plan of the Grotte des Fées as published by Cazalis de Fondouce in Materiaux, 1873 .

Figure 1. Plan of the Grotte de Cordes according to Cazalis de Fondouce (1873).

Hoskin and colleagues have established beyond reasonable doubt that the large majority of megalithic tombs in the central and western Mediterranean are oriented with respect to rising positions of the sun. In so doing, Hoskin notes the rather unique orientation of the Arles-Fontvieille monuments in the direction of the setting sun (Hoskin 2001) as opposed to the dominant tradition of monuments facing the rising sun. Although he notably fails to remark that this orientation might have as a function the production of a hierophany - as I have proposed - he does suggest that these sites were the center of a culture from which radiated a tradition of westerly oriented graves in a countercurrent to the dominant tradition of the Iberian peninsula and southern France. In doing so he relies heavily on the work of the late Yves Chevalier (1999) whose careful notation of the orientation of Provençal tombs/monuments was an invaluable contribution to archeaoastronomy.

Thus, while other researchers have noted the orientation of the Arles-Fontvieille monuments, none has suggested a possible functional explanation as has been done, for example, with the orientations of elements of Stonehenge or with the passage mounds of the Boyne Valley. This is an understandable lacuna. Unlike the passage mounds of the Boyne Valley, the hypogées of the Arles-Fontvieille group are not prominent surface monuments, rather they are subterranean monuments and it is far from immediately evident that a sunbeam could penetrate to any depth at all, let alone to the rear of the passage.

Since 1998, I have been able to observe and document the phenomenon at the Grotte de Bounias and the Grotte de la Source thanks to the gracious cooperation of the landowner. At the Grotte de la Source, which is the only monument whose entry is completely unobstructed by vegetation, I have captured a complete sequence of photographs documenting sunlight entering the monument at approximately 16:30 and striking the back wall at approximately 18:00 (Fig. 2). Future fieldwork will enable me to document this phenomenon simultaneously at multiple sites in order to obtain an exact record at each of the 
monuments and to document for what time period around the equinox the light enters and/or strikes the back wall. See also Fig. 3 for the Hypogée d'Arnaud-Castellet.

While I have been able to visit the Grotte de Cordes, this has not coincided with either the vernal or autumnal equinox, though plans are in place for future fieldwork during one of these periods.

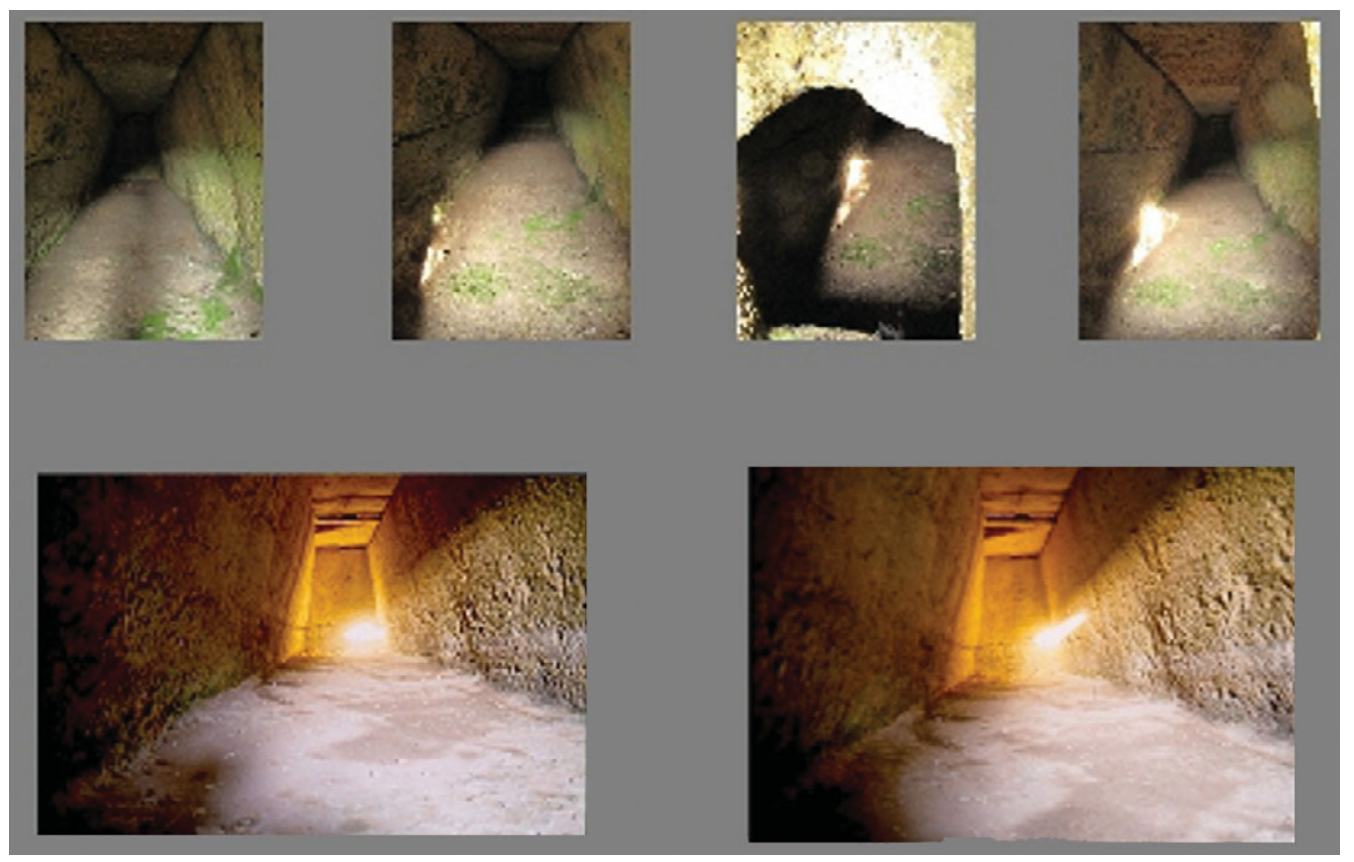

Figure 2. The setting equinoctial sunlight entering the Grotte de la Source. (c)Morgan Saletta.

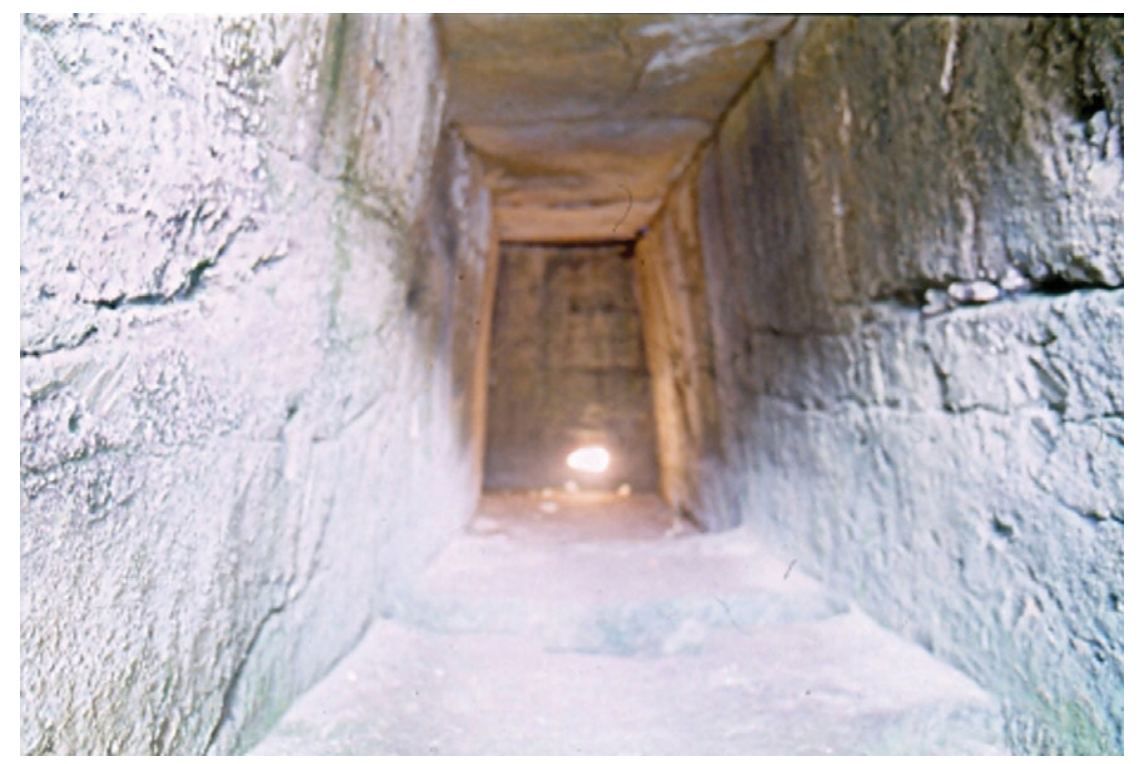

Figure 3. The setting equinoctial sunlight hitting the back wall of the Hypogée d'Arnaud-Castellet. (C)Morgan Saletta. 


\section{Hierophanies}

The equinox phenomenon that I have verified to date at three of the sites is similar to astronomically related hierophanies that have also been described at the passage tombs of the Boyne Valley in Ireland (Brennan 1983; Patrick 1974), Maes Howe in Scotland (MacKie 1997), and Gavrinis in Brittany (Le Roux 2011).

The term 'hierophany' is used frequently by Mircea Eliade to refer to a manifestation of the sacred. Cultural astronomers use it in a more limited and specific manner to refer to special plays of light and shadow that reinforce the symbolic and sacred nature of a place or space (Ruggles 2005). In addition to giving us important clues into the symbolic and cosmological significance of these monuments, my discovery of the functional nature of the equinoctial alignment and the hierophany produced is important for another reason.

As mentioned earlier, these monuments are frequently discussed as being significant and unique because of their unusual architecture (Guilaine 1998), some comparisons with passage mounds notwithstanding.

However, the equinoctial hierophany places the Arles-Fontvieille monuments firmly in a functional class with passage mounds such as those of the Boyne Valley where astronomically significant hierophanies are also produced both at the winter solstice as well as at (approximately at least) the equinox.

\section{The Pleiades and evidence of stellar observations}

In addition to the astronomical alignment of the monuments and the documented hierophany at three of the sites, there is also strong evidence for stellar observation in the form of rock art at one of the sites, the Grotte de la Source. These engravings (Fig. 4) have been variously remarked upon (Arnal \& Latour 1953; Daniel 1960; Montjardin 1974) but no detailed interpretation seems to have been made.

I speculate that these markings are a graphic representation of the daily movement of the sun (the crossed circle with the curving tail) and the heliacal rising and setting of two groups of stars, one of which I identify as being the Pleiades and the other more or less corresponding to the constellation Orion (as currently defined) (Fig. 5).

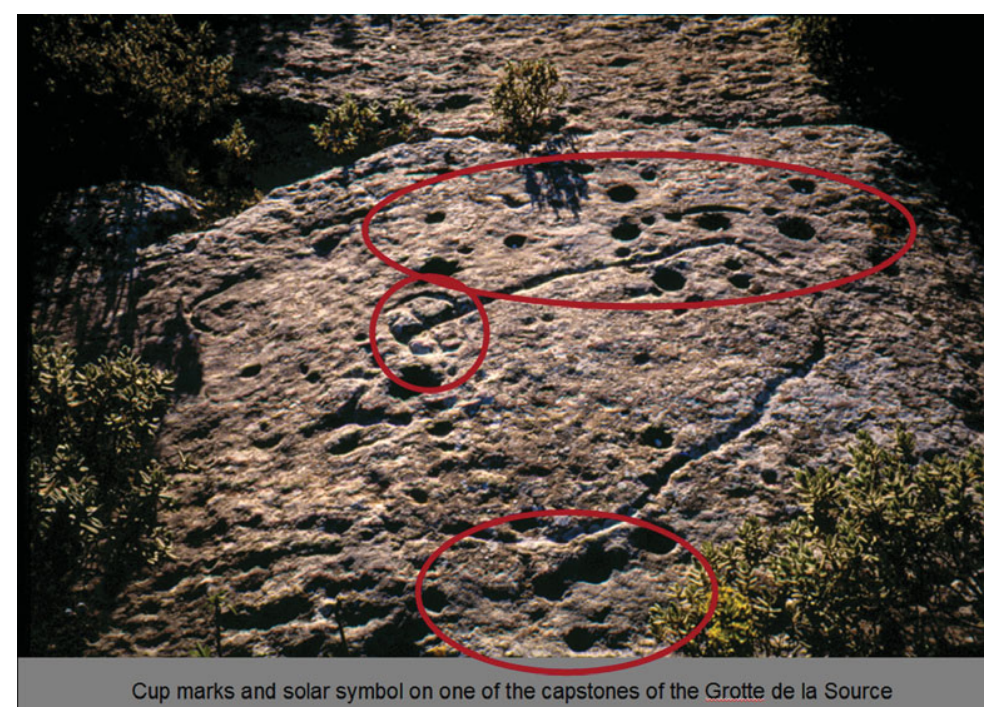

Figure 4. Engraved rock art on the capstone of the Grotte de la Source. 

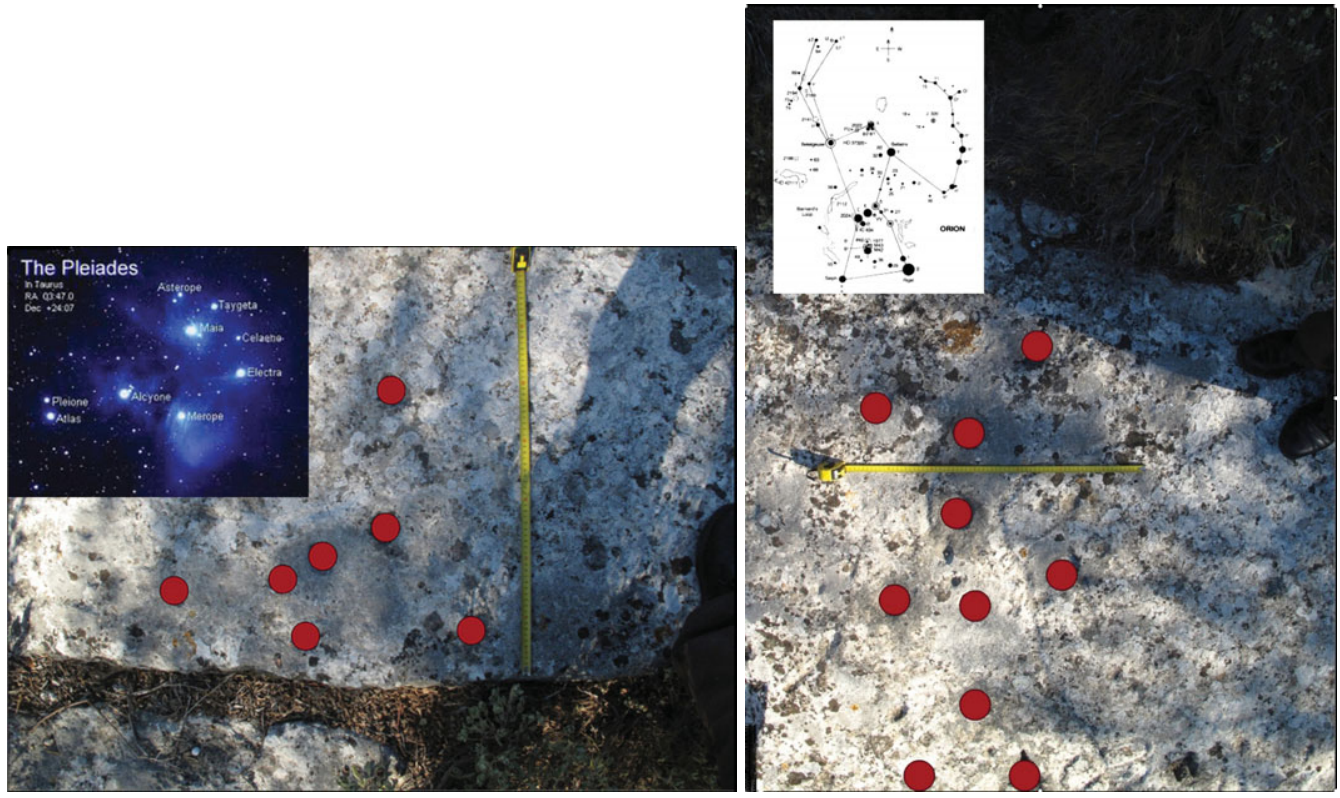

Figure 5. Cupmarks (overlayed in red) possibly representing (left) the Pleiades and (right) stars within Orion.

It should be noted that this may be an example of hidden art, in which the engravings were covered by a tumulus surmounting the monument in the past, and may also be the result of the reutilisation of another monument - as has been demonstrated to have occurred in the Morbihan (Le Roux 1982, 1998; L'Helgouac'h 1983). However, given the fact that the engravings appear to line up with the relative motion of the sun and the rising and setting positions of the asterisms (also roughly east-west) it seems likely that the engravings were purposefully positioned.

Asterisms have been used by many peoples for calendrical and timekeeping purposes, as recorded in abundant ethnographic and historical accounts, so it is not surprising that we find them used here. In the Mediterranean, the use of the heliacal rising of the Pleiades for the purposes of an agricultural calendar is first recorded in Hesiod's Works and Days (c. 700 BC) and is generally considered to be much older (Rappenglück 2008; Hoskin 2001).

Using a program developed by Karine Gadré (2010) of l'Institut de Recherche en Astronomie et Planétologie (Toulouse) I have calculated the heliacal rising and settings of various stars in these asterisms for the possible period of construction-approximately 3,000 BC (Guilaine 1998). It should be noted that factors such as humidity and the visual acuity of the observer can affect the date of the perceived heliacal rising or setting by as much as a week or so. As the program allows these to be set, I chose the average humidity level for present-day France (75\%) as suggested by Dr. Gadré, and a visual acuity of 1.5 on the Snellen scale (between good and excellent visual acuity).

Significantly, the heliacal setting of the Pleiades in 3000 BC (calculated by the heliacal rising of Sterope) occurs roughly one month before the vernal equinox (12 February), while the heliacal rising of the Pleiades occurs roughly a month and a half after the vernal equinox (10 May).

With respect to Orion, the heliacal settings of Rigel (25 February), Mintaka (2 March), and Betelgeuse (18 March) occur in the period after the heliacal setting of the Pleiades 
but before the equinox, with the heliacal setting of Betelgeuse nearly coinciding with the equinox.

Equally important perhaps is the fact that the heliacal rising of these same stars within Orion also have an interesting relationship to the summer solstice, with the heliacal rising of both Rigel (28 June) and Mintaka (26 June) occurring within the week after the solstice and that of Betelgeuse (10 June) some 11 days earlier. While there is no direct evidence for solstitial observations at the Arles-Fontvieille monuments, it seems highly likely that the solstices would have had ritual significance to the builders.

Given that the period both immediately before and after the vernal equinox would include the planting period for many crops, the stellar observations of heliacal settings, together with an accurate date for the vernal equinox, likely based at least in part on observations of the sunlight in the chambers, would provide a highly useful calendrical tool for the agricultural activities of the monument builders. Furthermore, the autumnal equinox hierophany would have highlighted autumn, the seasonally opposite period to the spring equinox, marked by the harvest and the coming onset of winter.

\section{Timekeeping, cosmology and landscape}

It is highly likely that timekeeping was intimately connected with ritual and cosmology, and that the creation of these monuments was intricately linked to sacred conceptions of place, landscape, time, the heavens and seasonal cycles of life and death. Gaining an understanding of the astronomical significance of these sites allows us to better understand the sacred and cosmological landscape that the builders of the Arles-Fontvieille monuments created. The monuments and their relationship to the cosmos and the landscape around them might well benefit from a phenomenological approach such as Tilley's (1994) suggestion that groupings of monuments be considered as a 'network', creating areas of sacred belongingness.

Looking at the plan of the sites, and particularly the Grotte de Cordes with its two circular side chambers, it is difficult not to see a complex dual sexual symbolism involving the penetrating ray of sunlight into a monument that is itself both phallic in shape while the interior space can be seen as both tomb and potentially as a womb. Here we have incredibly fertile ground for an exploration, drawing on both ethnographic and historical sources, of (for example) the symbolism of sky god, earth mother, and cycles of death, rebirth, of planting and harvest and the change of seasons from winter to spring and summer to autumn that roughly correspond in time to the equinoxes in the temperate northern hemisphere. The field of cultural astronomy and its strong interdisciplinary connections permits the researcher to pursue these topics from a strong disciplinary base though space does not allow an in-depth exploration of this topic in the present paper.

\section{Hierophany or theophany: pinhole aperture effects and projected solar images}

There is a further speculative possibility regarding the lighting effect produced by a narrow shaft of sunlight penetrating a small aperture or entrance such as occurs at the Arles-Fontvieille monuments and other monuments such as those in the Boyne Valley in Ireland. I speculate that the builders of these monuments may have been exploiting the camera obscura effect to project a solar image into the interior of the monuments. The principles of the pinhole camera and camera obscura have been understood for millennia (Hammond 1981). Indeed, camera obscura effects produced by small holes in tents or small openings into caves have been proposed as one possible 'origin of art theory' and 

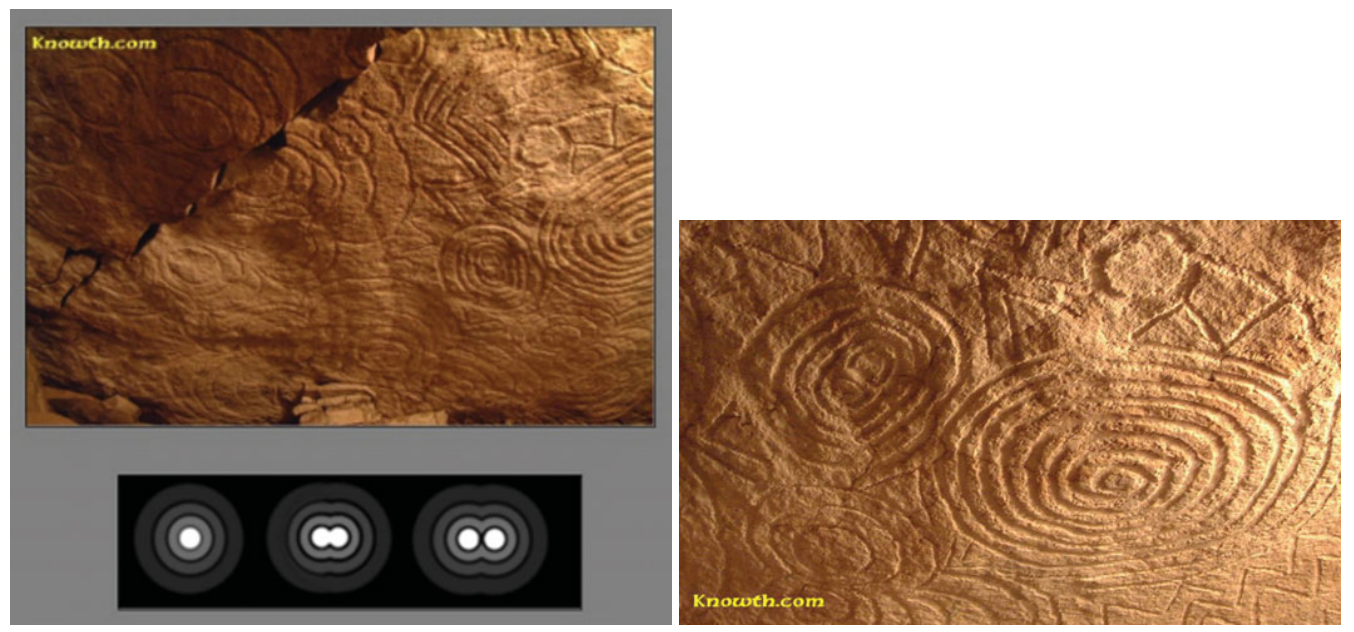

Figure 6. Rock art on the roof stone of the eastern recess of Newgrange and comparison with Airy disks from one and two point sources. Newgrange photos (CKnowth.com; Airy disk (C) CSIRO (2006).

since my presentation of this hypothesis at the 2010 SEAC conference it has come to my attention that a team of researchers led by the artist Matt Gatton has recently proposed a similar hypothesis with respect to the Boyne Valley monuments - specifically Cairn T at Loughcrew (Gatton et al. 2010).

That the builders of the Arles-Fontvieille monuments would have been familiar with pinhole effects is certainly far from implausible. They might have been observed through a hole in a tent or dwelling or, as Aristotle in the 4th century BC remarked in Problems Book VX (Aristotle 1936), during a solar eclipse when a myriad of small eclipse images were projected onto the ground by light passing through a broad-leafed tree.

It should be noted however that, whether intentional or not, the bright spot of light that appears on the back wall of the monuments is indeed a projected solar image, albeit fuzzy and out of focus owing to the refraction produced both at the lip of the entrance ramp and at the portal/aperture itself. It would certainly be possible to produce a clear and focussed solar image by limiting the entrance aperture and plans are in place to experiment with this during further field research.

I would also like to briefly present the highly suggestive fact that the characteristic diffraction rings (Airy disk) produced by a point source of light through a small aperture bear a close resemblance to the concentric circles and rings carved on the roof stone at Newgrange (Fig. 6). Of course, this resemblance may be purely coincidental but it is striking - and it is possible that the exploitation of one or multiple apertures to create visual plays of light within the monuments might be one explanation for the artwork at Newgrange as well as at sites with similar motifs such as at Gavrinis.

In any case, the interior play of light produced by the sun's rays penetrating the site would almost certainly have been ritually exploited, in line with Bradley's (1989) suggestion that megalithic tombs and monuments, particularly passage tombs, were deliberately designed to create zones of light and darkness within the monument, probably with specific ritualistic purpose.

Indeed, if we assume that the heavenly bodies were conceived as sacred and/or as deities, which seems almost certain, then the projection of the image of the sun into the interior of a monument then becomes not merely a hierophany (a manifestation of the sacred), but a literal theophany or a manifestation of a deity - in this case the solar deity. 


\section{Conclusion}

The evidence that the megalithic monuments of Arles-Fontvieille were astronomically aligned to produce a hierophany on and around the equinox (together with evidence of stellar observations) suggests that these remarkable architectural achievements were much more than mere tombs. It seems likely they were sites of seasonal ritual and cosmological importance perhaps more akin to medieval cathedrals, which too had burials and ossuaries but were certainly far more than mere houses of the dead.

I will follow other authors, notably Guilaine, in suggesting that these sites were much more than mere houses of the dead or necropoleis. It seems clear, particularly in the light of the astronomical alignment and the hierophany it produces - together with the small number of human remains at some of the sites and total absence thereof at the Grotte de Cordes (Guilaine 1998) - that these were monuments of complex ritual importance that embodied cosmological principles as well as being clear manifestations of social power.

Moreover, despite architectural differences, the Arles-Fontvieille monuments are clearly in a functional class with the Boyne Valley monuments, a class defined by the use of long passages and limited openings to produce light-and-shadow hierophanies related to seasonally important astronomical events. In light of this, it seems reasonable to ask the question what if any relationship these monuments had to each other. They seem to have been built during roughly the same time period (though exact chronologies are not available) and by admittedly different and geographically distant cultures - but do the similarities in their architectural function signal that there was an exchange or diffusion of ideas between these regions? Were there large-scale networks in the sense that Bradley \& Edmonds (1993) envisage for Neolithic Britain, that linked, however tenuously, across distance and time, these important monumental centers? Certainly there have been many suggestions of a connection between the Morbihan monument of Gavrinis and those of the Boyne Valley (O'Kelly 1982; Eogan 1986) and it seems reasonable that at least some contact occurred between southern France and Brittany. The Arles-Fontvieille monuments were probably built in the middle to late Neolithic period and it is reasonable to ask whether their astronomical function and the hierophany associated with it represents a unique local innovation, or rather if they and other sites represent local variations of a larger evolutionary tree that might include sites of very different form that also mark seasonally important astronomical events - from Stonehenge in England to Goseck in Germany, and Almendres in Portugal (da Silva 2010). Indeed, archaeoastronomers might ask themselves whether astronomically aligned monumentalism and certain types of ritualized timekeeping should be included as part of a Neolithic package (Tringham 1971) or Neolithic packages of culture and techniques.

These are open questions, and archaeoastronomical considerations are but one of many factors to be taken into consideration when attempting an answer. However, understanding these monuments in the context of European megalithism is as important today as it was when Glyn Daniel first posited their crucial importance. The nature of their equinoctial alignment and the evidence for observations of the heliacal rising of the Pleiades and Orion are important new factors which should be taken into account as we seek to better understand these as yet enigmatic monuments.

\section{Acknowledgements}

I would like to extend my heartfelt gratitude to Jacques and Diane des Cordes without whose ongoing hospitality, patience and cooperation this research would not have been possible. I would also like to express my gratitude to Dr. Gerhard Wiesenfeldt and the University of Melbourne for ongoing support for my research. 


\section{References}

Aristotle 1936, Problems, Books I-XXI, transl. W. S. Hett, Heinemann, London.

Arnal, J. \& Latour, J. 1953, Les hypogées et stations néolithique de la région d'Arles-enProvence. Études Roussillonnaises 111, 27-69.

Bradley, R. J. 1989, Darkness and light in the design of megalithic tombs. Oxford Journal of Archaeology 8(3), 251-259.

Bradley, R. J \& Edmonds, M. 1993, Interpreting the Axe Trade, Cambridge University Press, Cambridge.

Brennan, M. 1983, The Stars and the Stones, Thames \& Hudson, London.

Cazalis de Fondouce, P. 1873, Les Temps Préhistoriques dans le Sud-Est de la France, Allées Couvertes de la Provence, Delahaye, Paris.

Chevalier, Y. 1999, Orientations of 935 dolmens of southern France. Archaeoastronomy no. 24 (suppl. to Journal for the History of Astronomy 30), S47-S82.

CSIRO 2006, Resolution and Sensitivity, http://outreach.atnf.csiro.au/education/senior/ astrophysics/resolution_sensitivity.html (accessed Nov. 11, 2010).

Daniel, G. 1960, The Prehistoric Chamber Tombs of France, Thames \& Hudson, London.

da Silva, C. M. 2010, Neolithic cosmology: the equinox and the spring full moon. Journal of Cosmology 9, 2207-2216.

Eogan, G. 1986, Knowth and the Passage Tombs of Ireland, Thames \& Hudson, London.

Gadré, K. 2010, Logiciel de Détermination des Dates de Coucher et de Lever Héliaques d'une Étoile 2010. Computer program, Culture Diff, Toulouse.

Gatton, M., Carreion, L., Cawein, M., Brock, W., \& Scott, V. 2010, The camera obscura and the origin of art: the case for image projection in the Paleolithic. In G. Kumar and R. Bednarik (eds), Official Proceedings of the XV World Congress of the Union Internationale des Sciences Préhistoriques et Protohistoriques (UISPP) 35, Global State of the Art-SO7, Archaeopress, Oxford.

Guilaine, J. 1998, Au Temps des Dolmens, Éditions Privat, Toulouse.

Hammond, J. H. 1981, The Camera Obscura. A Chronicle, Adam Hilger Ltd, Bristol.

Hoskin, M. A. 2001, Tombs, Temples and their Orientations, Ocarina Books, Bognor Regis.

L'Helgouac'h, J. 1983, Les idoles qu'on abat. Bulletin de la Société Polymatique du Morbihan $110,57-68$.

Le Roux, C-T. 1982, A propos fouilles de Gavrinis (Morbihan): Nouvelles données sur l'art megalithique armoricain. Bulletin de la Société Préhistorique Française 81, 89-96.

Le Roux, C-T. 1998, L'art de Gavrinis. Dossiers d'Archaeologie 229, 28-36.

Le Roux, C-T. 2011, Megalithes du Morbihan, Ministère de la Culture et de la Communication, http://www . culture.gouv.fr/fr/arcnat/megalithes/ (accessed 2 Jan. 2011).

MacKie, E. W. 1997, Maeshowe and the winter solstice: ceremonial aspects of the Orkney Grooved Ware culture. Antiquity 71, 338-359.

Montjardin, R. 1974, Le dolmen du Méandre de Gen (Ardèche). Études Préhistoriques, 10-11, $1-15$.

O'Kelly, M. 1982, Newgrange: Archaeology, Art, and Legend, Thames \& Hudson, London.

Patrick, J. D. 1974, Midwinter sunrise at Newgrange. Nature 249, 517-519.

Rappenglück, M. 2008, The Pleiades and Hyades as celestial spatiotemporal markers in the astronomy of archaic and indigenous cultures. In G. Wolfschmidt (ed.), Prähistorische Astronomie und Ethnoastronomie, Bücher von Frauen, Berlin.

Ruggles, C. L. N. 2005, Ancient Astronomy: an Encyclopedia of Cosmologies and Myth, ABCCLIO, Santa Barbara.

Sauzade, G. 1977. Le dolmen de Coutignardes, commune de Fontvieille (Bouche-du-Rhône). In Congrès Préhistorique de France, $X X^{e}$ session, Provence, 1974, Société Préhistorique Française, Paris, pp. 567-580.

Tilley, C. 1994, A Phenomenology of Landscape. Places, Paths and Monuments, Berg, Oxford.

Tringham, R. 1971, Hunters, Fishers, and Farmers of Eastern Europe: 6000-3000 BC, Hutchinson, London. 